these behaviours within individual groups. Indian (OR: 1.76; 1.14, $2.71)$ and Chinese (OR: $3.65 ; 1.37,9.78)$ groups were more likely to be obese in the second generation than the first after adjusting for age and sex, with no significant differences observed in all other groups. Adjusting for health behaviours in each ethnic minority group had a negligible impact on the risk of second generation obesity. However, the risk of obesity increased in all groups after adjusting for the better socioeconomic circumstances of the second generation.

Conclusions Socioeconomic shifts determine generational differences in obesity risk to a greater extent than acculturative changes in behaviours. Findings suggest that generational variation in obesity rates for ethnic minorities may be more effectively controlled through reductions in wider socioeconomic inequalities rather than targeting individual health related behaviours.

\section{P45 REGIONAL COMPARISON OF SOCIOECONOMIC AND ENVIRONMENTAL PROFILES OF FAMILIES WITH PREGNANT WOMEN IN THE ALL IRELAND TRAVELLER HEALTH STUDY}

doi:10.1136/jech.2010.120477.45

N A Hamid, S Abdalla, J Turner, B Quirke, R Niccharthaigh, C Kelleher, P Fitzpatrick, for the All Ireland Traveller Health Study group. School of Public Health, Physiotherapy and Population Science, University College Dublin, Ireland

Objective Travellers have been documented as a distinct group in Irish society for centuries. They experience significant socioeconomic and health disadvantage particularly pertinent to pregnancy and early childhood development. This analysis contrasts the socio-economic and environmental profiles of "families with a resident pregnant woman" (FRPW) to other Traveller families and according to two distinct geopolitical regions.

Setting Census survey of the All Ireland Traveller Health Status Study of 10618 Traveller families in the Republic of Ireland (ROI) and Northern Ireland (NI).

Methodology Cross-sectional descriptive analysis of all FRPW in recruitment stage of prospective birth cohort study.

Results General comparison of socio-economic indicators showed marked differences between regions. There were $42 \mathrm{FRPW}$ in NI (2.7\% of all census families), $670(7.4 \%)$ in ROI. FRPW family size was smaller in NI (mean 2.7, median 2, SD 1.9) compared to ROI (mean 4.1, median 4, SD 2.6) $(\mathrm{p}=0.001)$. Literacy rate was better in FRPW compared to non-FRPW in ROI but not in NI. However, there were no differences in literacy and numeracy rates for FRPW between regions. More FRPW in NI than ROI live in caravan/mobile home/trailer (40.5\% NI vs $20 \%$ ROI, $\mathrm{p}<0.001)$; stayed for shorter period in their current accommodation $(47.6 \% \mathrm{NI}$ vs $33.5 \%$ ROI, $\mathrm{p}=0.002)$ and were forced to move by local community $(12.2 \% \mathrm{NI}$ vs $2.6 \%$ ROI, $\mathrm{p}<0.001)$. FRPW in NI have better private transport ownership (83.3\% vs $79.6 \%$ ROI, $\mathrm{p}<0.001$ ). There was a greater lack of general public facilities for example, working public lighting and fire hydrants, and more problems with living environment for example, lodged water $(22.9 \%$ ROI vs $10 \% \mathrm{NI})$ and living near a road side $(48.4 \%$ ROI vs $35 \% \mathrm{NI}$ ) (all $\mathrm{p}<0.001$ ) in ROI compared to NI. These varied across the type of accommodation and may be associated with poor quality living accommodation. There was a significant difference in the reporting of perceived "very unhealthy/ unhealthy" (40.5\% NI vs $25.3 \%$ ROI; p $<0.001)$ and "very unsafe/ unsafe" (40.5\% NI vs $27.3 \%$ ROI) living environment.

Conclusion FRPW suffer from different socioeconomic and environmental amenity disadvantages in the regions; such differences may reflect overall regional differences rather than be related specifically to pregnancy. In both jurisdictions health needs are considerable with significant policy indications.

\section{P46 ETHNIC DIFFERENCES IN PACE OF GROWTH BETWEEN BIRTH AND 5 YEARS: RESULTS FROM THE MILLENNIUM COHORT STUDY}

doi:10.1136/jech.2010.120477.46

E Lenguerrand, S Harding. Medical Research Council, Social and Public Health Sciences Unit, University of Glasgow, Glasgow, UK

Objective Size at birth and accelerated postnatal growth are linked to obesity and cardiovascular disease (CVD) in adulthood. CVD is more common in Black African and South Asian origin populations in the UK. Little is known about growth trajectories of ethnic minority children in the UK. Overweight is more common in some ethnic minority groups in adolescence. We examined ethnic differences in growth between birth and 5 years (y).

Design Millennium Cohort Study, a UK population-based cohort study.

Setting England.

Participants White (6361), Black Caribbean (152), Black African (250), Indian (328), Pakistani (645) and Bangladeshi (265) infants born in 2000-2001, $\geq 2500 \mathrm{~g}, \geq 36$ weeks gestation, with no physical disability.

Main Outcome Measures Weight, height, body mass index (BMI) and age-standardised Z-scores (based on the British 1990 growth reference). Weight was measured at birth, 9 months, $3 \mathrm{y}$ and $5 \mathrm{y}$ and linear mixed models were used to estimate differences in the weight trajectories and to identify potential differential effects from maternal characteristics (age and smoking status at delivery, education, psychological well-being, diabetic status), household socio-economic circumstances (SEC) (employment, poverty level), and feeding practices (duration of breastfeeding, age at first solid food).

Results Compared with White infants, mean birth weights of Indian, Pakistani Bangladeshi and Black Caribbean infants were lower by $180-410 \mathrm{~g}$ while that of Black African infants were similar. Relative to the standard, all ethnic groups experienced faster weight gain notably between $0-3 y$. Average weight gains between $0-5$ y were greater for Black Caribbeans (boys $+0.88 \mathrm{sd} /$ year, girls +0.37 sd/year) and Black Africans (+0.78/year, +0.30/year) than for Whites $(+0.45 /$ year, $+0.17 /$ year). The increase was non-linear with slowest weight gain as age increased especially for Black Caribbeans and Africans boys $\left(-0.18 \mathrm{sd} / \mathrm{y}^{2}, 95 \% \mathrm{CI}-0.23\right.$ to -0.14$)$. By age $5 \mathrm{y}$, these groups were the heaviest but also the tallest. Larger BMIs were observed for Black Caribbean boys (1.32, 0.71 to 1.94) and Black African girls $(0.97,0.72$ to 1.22$)$ than their White peers. At this age, Black Caribbean boys $(56.2 \mathrm{~cm}, 53.9$ to 58.6$)$ and Black African girls $(55.8 \mathrm{~cm}, 54.7$ to 56.8$)$ also had larger waist circumference than Whites (boys $53.7 \mathrm{~cm}$, girls $53.5 \mathrm{~cm}$ ). There were no ethnic specific effects from maternal factors, household SEC or feedings practices. Conclusions A pattern of lighter birth weights and rapid growth was observed for Black Africans origin children compared with White children. The growth patterns observed here may be pertinent to the development of ethnic differences in CVD.

\section{P47 COUNTRY OF BIRTH OF MOTHER AND RATES OF PRETERM BIRTHS AND LOW BIRTH WEIGHT IN ENGLAND AND WALES OF BABIES OF AFRICAN AND CARIBBEAN ETHNICITY}

doi:10.1136/jech.2010.120477.47

P Datta-Nemdharry, A Macfarlane, N Dattani. City University London, London, UK

Introduction Preterm birth and low birth weight are associated with high rates of perinatal and neonatal morbidity and mortality. Some studies have shown associations between ethnic origin or country of 